\title{
CULTURA E IDENTIDADE SURDAS: ENCRUZILHADA DE LUTAS SOCIAIS E TEÓRICAS
}

\author{
Ana Paula Santana \\ Alexandre Bergamo*
}

\begin{abstract}
RESUMO: As expressões cultura e identidade surdas têm se legitimado, principalmente, pela defesa da língua de sinais como sendo a língua natural dos surdos. Essa defesa se faz por meio de uma inversão teórica que toma a língua, num primeiro momento, como determinada pelas práticas e interações sociais e, num segundo, faz dela a definidora dessas mesmas práticas. Este artigo discute os mecanismos de legitimação dessa inversão e suas implicações sociais e teóricas.
\end{abstract}

Palavras-chave: Cultura surda. Identidade surda. Língua de sinais. Lingüística.

\section{DEAF CULTURE AND DEAF IDENTITY: CROSSROAD OF SOCIAL AND THEORETICAL STRUGGLES}

ABSTRACT: The expressions deaf culture and deaf identity have been legitimated, mainly, through the defense of sign language as being the natural language of deaf people. This defense is made through a theoretical inversion that takes the language as determined for the practical and social interactions and the proper language define these same practical. This article argues about the mechanisms of legitimation of this inversion and its social and theoretical implications.

Key words: Deaf culture. Deaf identity. Sign language. Linguistic.

* Doutora em lingüística e professora do Curso de Fonoaudiologia e do Mestrado em Distúrbios da Comunicação da Universidade Tuiuti do Paraná. E-mail: ana.santa2@utp.br

** Doutorando em sociologia e professor do Departamento de Sociologia e Antropologia da Universidade Estadual Paulista (UNESP, Marília).E-mail: bergamo@marilia.unesp.br 

uero entender o que dizem. Estou enjoada de ser prisioneira desse silêncio que eles não procuram romper. Esforço-me o tempo todo, eles não muito. Os ouvintes não se esforçam. Queria que se esforçassem" (Labourit, 1994, p. 39). O depoimento de Labourit explicita um conflito: um esforço unilateral (dos surdos) para interagir com os ouvintes, e estes, por não se esforçarem, por discriminarem os surdos, acabam dando visibilidade a essa segregação e permitindo a "constituição" de um grupo diferente que acredita ter também uma cultura diferente.

Os surdos sempre foram, historicamente, estigmatizados, considerados de menor valor social. Afinal, faltava-lhes a característica eminentemente humana: a linguagem (oral, bem entendido) e suas virtudes cognitivas. Sendo destituídos dessas "virtudes", os surdos eram "humanamente inferiores". ${ }^{1}$ A língua de sinais era considerada apenas uma mímica gestual, e sempre houve preconceitos com relação ao uso de gestos para a comunicação. ${ }^{2}$ A exclusão profissional e social dos surdos ainda hoje confirma que a linguagem pode ser fonte de discriminação e de organização social restritiva. Essa discriminação não ocorre apenas quando há diferenças de nacionalidade, cor, perfil socioeconômico ou religião. Entre os surdos e os ouvintes há uma grande diferença que os distingue: a linguagem oral.

Assim, os surdos são, não raras vezes, situados a meio caminho entre os ouvintes, considerados humanos de qualidade superior, ou humanos em toda a sua plenitude, e os subumanos, desprovidos de todos os traços que os assemelham aos seres humanos. Eles não podem ser classificados como subumanos porque apresentam traços de humanidade, mas também não conseguem ser aceitos como seres humanos em sua plenitude. A defesa e a proteção da língua de sinais, mais que significar uma auto-suficiência e o direito de pertença a um mundo particular, parecem significar a proteção dos traços de humanidade, daquilo que faz um homem ser considerado homem: a linguagem.

A separação entre grupos humanos é produzida socialmente, bem como sua integração, na medida em que toda forma de preconceito, toda discriminação, todo comportamento humano está subordinado à cultura que os constrói, propaga, veicula e sedimenta. ${ }^{3}$ São as normas sociais que "autorizam" essa separação, normas que organizam toda a nossa vida social, modos de falar, de vestir-se, de atuar no mundo, de pensar etc. $\mathrm{O}$ modo como a surdez vem sendo descrita está ideologicamente relaciona- 
do a essas normas. Assim como a luta política por novas normas: cultura e identidade surdas, inclusão do surdo nas minorias sociais, junto com os negros e índios. Essa luta pela inclusão é uma forma de "garantia" de afastamento da "anormalidade" e aproximação das minorias, normais embora diferentes.

Essa mudança de estatuto da surdez, de patologia para fenômeno social, vem acompanhada também de uma mudança de nomenclatura, não só terminológica, mas conceitual: de deficiente auditivo para surdo, ou ainda Surdo. Antes, os surdos eram considerados deficientes e a surdez era uma patologia incurável. Agora, eles passaram a ser "diferentes". Deficiente auditivo e surdo, ou Surdo, como preferem autores como Moura (2000), por exemplo, são termos ideologicamente marcados. ${ }^{4}$

Conferir à língua de sinais o estatuto de língua não tem apenas repercussões lingüísticas e cognitivas, tem repercussões também sociais. Ser normal implica ter língua, e se a anormalidade é a ausência de língua e de tudo o que ela representa (comunicação, pensamento, aprendizagem etc.), a partir do momento em que se configura a língua de sinais como língua do surdo, o estatuto do que é normal também muda. Ou seja, a língua de sinais acaba por oferecer uma possibilidade de legitimação do surdo como "sujeito de linguagem". Ela é capaz de transformar a "anormalidade" em diferença, em normalidade. ${ }^{5}$

\section{A identidade surda}

Os defensores da língua de sinais para os surdos afirmam que é só de posse desta, considerada "natural", adquirida em qualquer idade, que o surdo constituirá uma identidade surda, já que ele não é ouvinte (Perlin, 1998; Moura, 2000). A maioria dos estudos tem como base a idéia de que a identidade surda está relacionada a uma questão de uso da língua. Portanto, o uso ou não da língua de sinais seria aquilo que definiria basicamente a identidade do sujeito, identidade que só seria adquirida em contato com outro surdo. O que ocorre, na verdade, é que, em contato com outro surdo que também use a língua de sinais surgem novas possibilidades interativas, de compreensão, de diálogo, de aprendizagem, que não são possíveis apenas por meio da linguagem oral. A aquisição de uma língua, e de todos os mecanismos afeitos a ela, faz com que se credite à língua de sinais a capacidade de ser a única capaz de oferecer uma identidade ao surdo. 
O que está por trás de tal afirmativa não é simplesmente uma questão de identidade social, mas, mais especificamente, uma identidade concebida a partir de um determinado pressuposto teórico. Ao tomar a língua como definidora de uma identidade social, ainda que se leve em conta as relações e os conflitos relativos às distintas posições ocupadas por grupos sociais, enfatiza-se o seu caráter instrumental. Assim, sua natureza, ou sua significação social, passa a ser creditada às interaçôes sociais às quais está ligada. Dessa forma, para alguns autores a identidade está relacionada tanto aos discursos produzidos quanto à natureza das relaçôes sociais. Para Maher (2001, p. 116), por exemplo, "ao falarmos de identidade, não estamos falando de essência alguma”. A identidade seria uma construção permanentemente (re)feita que buscaria tanto determinar especificidades que estabeleçam fronteiras identificatórias entre o próprio sujeito e o outro quanto obter o reconhecimento dos demais membros do grupo social ao qual pertence. Seria, portanto, nessa relação, no tempo e no espaço, com diferentes outros que o sujeito se construiria. É, com isso, nas práticas discursivas que o sujeito emerge e é revelado. Ou seja, é principalmente no uso da linguagem - e não qualquer materialidade lingüística específica que as pessoas constroem e projetam suas identidades. "A construção da identidade não é do domínio exclusivo de língua alguma, embora ela seja, sempre, da ordem do discurso" (Maher, 2001, p. 135) e, portanto, interativa e social.

Mas o fato é que não existe uma identidade exclusiva e única, como a identidade surda. Ela é construída por papéis sociais diferentes (pode-se ser surdo, rico, heterossexual, branco, professor, pai etc.) e também pela língua que constrói nossa subjetividade. Utilizando a expressão de Cameron et al. (apud Lopes, 2001, p. 310), "a pessoa é um mosaico intrincado de diferentes potenciais de poder em relações sociais diferentes”. Nesse caso, não há escolhas nas nossas identidades, isso independe da nossa mera vontade. Elas são determinadas pelas práticas sociais, impregnadas por relações simbólicas de poder. E, é obvio, essas práticas sociais e essas relações simbólicas de poder não são estáticas e imutáveis ao longo da vida dos sujeitos.

Esse é justamente o ponto que interessa aqui. Se a identidade está relacionada a práticas sociais de uma complexidade muito maior, por que a língua, e apenas ela, é tomada como o instrumento por excelência de sua constituição e definição? Qual é o significado dessa inversão, desse jogo teórico que toma a língua, num primeiro momento, como determi- 
nada pelas práticas e interações sociais e, num segundo, faz dela a definidora dessas mesmas práticas?

Para ilustrar melhor essa questão, que nos remete ao problema da constituição da identidade, vejamos alguns relatos: ${ }^{6}$

Paula: // escreve "pensei que eu era a única surda do mundo"// Porque ouvinte fala. Eu olhava para sua boca e não compreendia. Não sabia por que eu não podia falar. Ficava decepcionada // escreve "decepcionada" // Tentei descobrir por que eu não podia falar (...) Surdo nasce. A mãe ensina a falar, a estudar. Não sabe sinais. Não pode fazer sinais. Fazer sinais implica ser acomodado e não falar. Assim, ele cresce sem conhecer sinais e aprende a falar desde pequeno. Cresce sem nunca ter encontrado outro surdo. Um dia, ele vai passando na rua e encontra um surdo fazendo sinais. Ele olha para os movimentos das mãos e estranha. Pergunta ao surdo: "Você não ouve?". "Não. Sou surdo. Todos aqui são." "Eu também sou. Eu não escuto. Eu só falo." Vê os sinais e pergunta: "O que é isso? Eu não sei. Eu queria aprender". Ele começa a aprender língua de sinais. Depois, em casa, com a família, não se sente bem em falar. Não quer mais falar. Quer aprender a língua de sinais. ${ }^{7}$

Emanuelle Labourit (1994): Não havia compreendido que eu era surda. Somente que existia uma diferença (op. cit., p. 25). Nunca havia visto surdos adultos, portanto, na minha cabeça, os surdos nunca cresciam. Iríamos morrer assim, pequenos (op. cit., p. 32). Essa lógica cruel permanece enquanto as crianças surdas não se encontram com um surdo adulto. Elas têm necessidade dessa identificação com os adultos, uma necessidade crucial. É preciso convencer todos os pais das crianças surdas a colocá-las em contato o mais rápido possível com adultos surdos, desde o nascimento. Ela se construirá longe daquela solidão angustiante de ser a única no mundo, sem idéias construtivas e sem futuro (op. cit., p. 49). Para quem se habituou a virar a cabeça ao chamado de seu próprio nome, é talvez difícil entender. Sua identidade está dada desde o nascimento. Não têm necessidade de pensar nela, não se questionam, sobre si mesmos. São "eu”, naturalmente, sem esforço. Eles se conhecem, se identificam, se apresentam aos outros com um símbolo que os representa, mas a Emanuelle surda não sabia que ela era eu (op. cit., p. 51). Naquela idade, sentia-me pouco como uma estrangeira em minha própria família. Não tinha cumplicidade com alguém semelhante a mim. Não podia me identificar (op. cit., p. 56). Eu tinha [após a aquisição da língua de sinais] tantas perguntas a fazer. Tantas e tantas. Estava ávida, sedenta de respostas que podiam me responder (op. cit., p. 52).

Investigadora: Explica pra mim um pouco como é essa questão de identidade surda que você falou. Como é que é isso?

José: A identidade surda é aceitar ser surdo. Se a pessoa não aceita ser surda, só, não tem identidade própria. É... ele fica revoltado. Não aceita. Ele tem 
vergonha de ser surdo. Eu não... Eu não tenho vergonha de ser surdo. Eu exponho o meu problema, o que foi que causou. Então, eu exponho minha identidade de surdo, entendeu? Agora, tem surdo que tem vergonha, daí ele esconde a identidade dele.

No primeiro e no segundo casos, o discurso reconstrói as trajetórias de isolamento social de cada uma e faz da língua de sinais o passaporte de entrada para o universo social. Só que o universo social não se esgota aí. A partir do momento em que essa entrada teve início, o sujeito poderá ocupar novas posições sociais e ampliar as possibilidades ligadas a uma multiplicidade de práticas e interações sociais. A inserção no universo social teve, portanto, apenas início.

Já o caso de José mostra que o isolamento social a que nossa sociedade condena os surdos pode ser quebrado de outras maneiras. Em outro momento da entrevista, ele ressalta que sua primeira língua é a linguagem oral, e que, ao comunicar-se, prefere também usar a fala. José só utiliza a língua de sinais com surdos que não falam ou com ouvintes que queiram treinar a língua de sinais. Neste sentido, a linguagem oral também pode constituir a identidade do surdo, e não só a língua de sinais, a partir do momento em que o surdo dela se apropria e a molda para construir e marcar sua identidade. Mais significativo ainda se torna o caso dele se levarmos em conta que se trata do presidente de uma associação de surdos de uma importante cidade do interior paulista. Portanto, ocupa uma posição de autoridade e legitimidade perante a comunidade surda. No seu caso, a "identidade surda" parece se constituir pela sua carência, pela privação, e por assumir a surdez como limitação. José também comentou, durante a entrevista, que na adolescência teve muita dificuldade para aceitar a surdez. Quando as moças falavam baixo e ele não entendia, por exemplo, sentia vergonha de dizer que era surdo. Só tempos depois passou a aceitar a surdez. É por isso que José se refere à identidade surda como aceitação da surdez.

Ao que parece, a constituição da identidade pelo surdo não está necessariamente relacionada à língua de sinais, mas sim à presença de uma língua que lhes dê a possibilidade de constituir-se no mundo como "falante", ou seja, à constituição de sua própria subjetividade pela linguagem $^{8}$ e às implicações dessa "constituição" nas suas relações sociais. Em outras palavras, torna-se estranha a afirmação de que todos os surdos só constituam sua identidade por intermédio da língua de sinais. Afinal de contas, não há uma relação direta entre língua específica e identidade 
específica. A identidade não pode ser vista como inerente às pessoas, mas sim como resultado de práticas discursivas e sociais em circunstâncias sócio-históricas particulares. O modo como a surdez é concebida socialmente também influencia a construção da identidade. O sujeito não pode ser visto dentro de um "vácuo social". Ele afeta e é afetado pelos discursos e pelas práticas produzidos.

Há estudos relacionados à surdez que vêm tratando esse tema de uma outra forma, como se a identidade fosse constituída apenas a partir de dois pólos: o dos ouvintes e o dos surdos. A identidade é construída sempre em relação a um determinado grupo ao qual se pertence, diferenciando-se de um outro, com o qual se estabelece uma relação de caráter negativo, ou seja, por oposição a ele. Com isso, a construção da identidade baseia-se num processo de "associação" a um determinado grupo, e de "dissociação" com relação a outros grupos. O pertencimento a um dado grupo expressa-se por meio do ethos grupal, do conjunto de valores e saberes partilhados (Mead, 1934; Rose, 1962). A identidade pode ser construída também tendo um ethos como referência negativa: o indivíduo não faz parte daquele grupo e também não faz parte de nenhum outro grupo que possa ser caracterizado como tendo um ethos próprio. Por exemplo: os conceitos de normal e patológico definem um ethos de referência, a normalidade, e afasta todo aquele que dele não se aproxima, reservando a todos o mesmo lugar social de patológico. Não há um ethos que possa caracterizar e definir aqueles que são "patologizados".

A identidade é, assim, constituída por diferentes papéis sociais que assumimos e que, vale salientar, não são homogêneos. Podem ser religiosos (católicos, evangélicos etc.), políticos (de direita, de esquerda, socialistas, sociais democratas etc.), funcionais (metalúrgicos, vendedores, médicos etc.), estéticos (clubbers, punks, hyppies etc.), de gênero (homens, mulheres). A distinção entre ouvintes e não-ouvintes, de certa maneira, cria um obstáculo teórico: define o grupo de "não-ouvintes" como sendo o único contexto no qual eles se inserem. A identidade, nesse caso, só pode ser construída de forma negativa. Mas a arquitetura social não se reduz a isso, evidentemente. Talvez o caso mais óbvio e que se opõe a tal redução da estrutura social seja o esforço que várias comunidades religiosas têm feito para terem os surdos como parte dos seus membros. Atualmente, a maior parte dos cursos de línguas de sinais é oferecida por comunidades evangélicas e, no Brasil, um de seus principais "expoentes" tem a seu lado, na tela de seu programa de televisão, alguém que faz a tradução simultânea do que 
ele diz para a língua de sinais. Não importa se os fiéis são surdos ou não, nesse momento eles "pertencem" a um grupo particular formado não apenas por surdos, mas por um grupo de pessoas que compartilha a mesma religião e por isso se identifica.

Em suma, dificilmente se pode falar de uma identidade surda. A constituição da identidade do sujeito está relacionada às práticas sociais, e não a uma língua determinada, e às interações discursivas diferenciadas no decorrer de sua vida: na família, na escola, no trabalho, nos cursos que faz, com os amigos. $\mathrm{O}$ reconhecimento dessa realidade seria o aprofundamento das discussōes sobre a identidade no campo da surdez, no qual se procura estabelecer uma "norma" com relação ao que é teoricamente chamado de identidade, e exigir que as análises correspondam a ela. Ou seja, uma norma de identidade, a identidade do surdo, e uma norma cultural correspondente, a cultura surda.

\section{A cultura surda}

Quando se pensa em cultura, o conceito recorrente é de um conjunto de práticas simbólicas de um determinado grupo: língua, artes (literatura, música, dança teatro etc.), religião, sentimentos, idéias, modos de agir e de vestir. Poche (1989) afirma que, por cultura, entende-se os esquemas perceptivos e interpretativos segundo os quais um grupo produz o discurso de sua relação com o mundo e com o conhecimento, ou qualquer outra proposição equivalente; a língua e a cultura são duas produções paralelas e, além disso, a língua é um "recurso" na produção da cultura, embora não seja o único. Pare ele, a língua é, neste sentido, um instrumento que serve à linguagem para criar, simbolizar e fazer circular sentido, é um processo permanente de interação social.

$\mathrm{Na}$ área da surdez encontra-se geralmente o termo "cultura" como referência à língua (de sinais), às estratégias sociais e aos mecanismos compensatórios que os surdos realizam para agir no/sobre o mundo, como o despertador que vibra, a campainha que aciona a luz, o uso de fax em vez de telefone, o tipo de piada que se conta etc. Kozlowski (2000), por exemplo, afirma que a existência de uma cultura surda faz parte da educação bilíngüe. $\mathrm{O}$ surdo seria bilíngüe e bicultural. $\mathrm{O}$ biculturalismo designa o conjunto de referências à história dos surdos, o conjunto de significações simbólicas veiculadas pelo uso de uma língua comum, o conjunto de estratégias sociais e de códigos sociais utilizados de maneira comum pelos 
surdos para viverem numa sociedade feita por e para os ouvintes. É, portanto, uma cultura de adaptação à diferença e produtora de elo social. A realidade e a legitimidade desta noção de cultura é objeto de grandes críticas, algumas vezes com razão, porque muitos aspectos da cultura surda se apresentam mais como um sistema derivado da cultura dos ouvintes do que como uma cultura realmente original e autônoma.

Já para Geertz (1989), o conceito de "cultura" é essencialmente semiótico, o homem seria um animal amarrado a teias de significados que ele mesmo tece. A cultura seria o conjunto dessas teias. A cultura não é apenas um complexo de padróes concretos de comportamento, costumes, usos, tradições, feixes de hábitos, é também um conjunto de mecanismos de controle, planos, receitas, regras e instruções para governar o comportamento. Segundo ele, o homem é precisamente o animal mais desesperadamente dependente de tais mecanismos de controle e estratégias. A perspectiva de cultura como um mecanismo de controle inicia-se com o pressuposto de que o pensamento humano é basicamente social e público, por isso seu ambiente natural é o pátio, o mercado, a praça da cidade. Assim, pensar consiste não nos acontecimentos na mente, mas num tráfego entre símbolos significantes: "Nossas idéias, nossos valores, nossos atos e até mesmo nossas emoções são, como nosso próprio sistema nervoso, produtos culturais, na verdade produtos manufaturados a partir de tendências, capacidades, disposições com as quais nascemos" (Geertz, 1989, p. 62).

Temos, pelo menos, dois modos de discutir essa questão. Um modo mais simples e que argumenta que os surdos, apenas por fazerem parte de um grupo que fala uma língua determinada, não podem ser considerados membros de uma outra cultura, já que cultura implica bem mais que se ter uma língua em comum. Dir-se-ia, assim, que cultura não é só uma língua: a língua, isoladamente, não totaliza uma cultura. Os surdos crescem segundo os valores, as crenças, os símbolos, os modos de agir e de pensar de um sistema socialmente instituído e em transformação. Encerrando a discussão, dir-se-ia que os surdos e os ouvintes crescem numa mesma cultura a partir do momento em que participam de um mesmo universo social. Valores, crenças e símbolos específicos não expressam uma cultura diferente, apenas indicam a particularidade de um grupo dentro de um sistema social dado. Em outras palavras: não há como conceber uma idéia de cultura surda e de seu oposto, cultura ouvinte. Porém, finalizar esta discussão com o enunciado acima seria uma 
formulação abstrata e descomprometida com a realidade, pois ignoraria a separação que a própria sociedade estabelece entre surdos e ouvintes e os motivos pelos quais se luta politicamente por essa separação.

Um outro modo de discutir a questão da cultura surda é bem mais complexo. Desse lado, não vale a pena entrar em jogos teóricos como, por exemplo, se existe ou não cultura surda e seu oposto, a cultura ouvinte. Esse tipo de trabalho seria apenas a ponta do iceberg. Em outras palavras, seria preciso entender por que persistem as opiniōes em favor da cultura surda e entender quais as vantagens em adotar (e defender) essa idéia. Assim, não parece interessante partir de uma idéia rígida e preconcebida do que seja ou não cultura. Há questões outras, não evidentes, e que são importantes para esta discussão, como, por exemplo: por que parece ser uma conclusão lógica para muitos autores e surdos a adoção do termo "cultura surda" e a ênfase no uso da língua como sua principal definição?"

Assumir a existência de uma "cultura surda", tanto no interior da comunidade surda quanto no interior do campo de pesquisas universitário, implica também assumir uma separação entre surdos e ouvintes. Implica referendar uma di-visão social específica. É por meio da constituição heterogênea dos grupos que se pode observar melhor a eficácia das representações que impõem os princípios de di-visão. Assim, a oficialização encontra sua plena realização na manifestação, ato típico mágico por meio do qual o grupo prático, negado, reprimido, torna-se visível, manifesto, tanto para os outros grupos como para si mesmo, atestando sua existência na qualidade de grupo conhecido e reconhecido, e afirmando sua pretensão à institucionalização. $\mathrm{O}$ mundo social é também representação e vontade. Existir socialmente é também ser percebido, aliás, percebido como distinto (Bourdieu, 1998).

No caso da surdez vemos que, longe de ser apenas um debate por direitos ou para tentar trazer melhorias ao surdo, a defesa da cultura surda acaba por atualizar os mecanismos de reprodução da própria desigualdade, e o termo "cultura" passa a ser um dos instrumentos de legitimação dessa desigualdade e da tentativa de preservar uma suposta homogeneidade atribuída aos grupos de surdos.

Acredita-se também que o termo "cultura surda" - e sua legitimação - seja produto exclusivamente dos surdos, ao passo que aos demais grupos da sociedade, ou melhor, aos ouvintes, é subtraída qualquer participação na construção do termo. Sob várias formas, para uma di-visão 
social com base em uma suposta cultura surda e outra ouvinte, todos aqueles que estão distantes da comunidade surda são considerados sem relevância e não podem contar como referência. Assim, toda idéia de cultura surda fica ligada exclusivamente ao surdo e aos profissionais da área, como se, inclusive, a criação do termo "cultura" fosse associada apenas a um grupo específico.

Grosso modo, a discussão da literatura em torno da cultura surda pressupõe uma diferença entre surdos e ouvintes e postula uma idéia de realidade homogênea a cada um dos pólos dessa dicotomia. Entretanto, essa diferença faz parte de um processo de cisão social que não é recente. $\mathrm{O}$ próprio discurso sobre a desigualdade também faz parte desse mesmo processo. Um processo que, ao invés de aproximar os surdos dos ouvintes, distancia-os, já que enfatiza sempre o que eles têm de diferente e nunca o que eles têm em comum.

Sá, por exemplo, partindo de uma concepção socioantropológica da surdez, afirma que não se está defendendo que o surdo faz parte de uma "raça" distinta da sociedade ou de sua família ouvinte:

(...) nem estamos pretendendo incentivar a criação de grupos à parte, de minorias alheias à sociedade majoritária. Pretendemos, sim, que sejam reconhecidas as variadas "especificidades culturais", manifestadas na língua, nos hábitos, nos modos de socialização e de funcionamento cognitivo que dão origem a uma cultura diferente (...). O objetivo de considerar, no estudo da problemática do surdo, a questão cultural não é o de incentivar a criação de grupos minoritários à margem da sociedade, mas justamente o contrário, ou seja, o de considerar a diferenciação lingüística como necessária para possibilitar o desenvolvimento normal da cognição, da subjetividade, da expressividade e da cidadania da pessoa surda. (Sá, 1999, p. 157-158)

A questão não é só de usos de línguas diferentes, mas o que implica o uso de línguas diferentes. O lógico parece ser que os falantes de uma mesma língua interajam mais que os falantes de línguas diferentes. A criação de grupos de surdos acaba sendo o reflexo disso. Ressalte-se aqui que nos grupos de surdos também há ouvintes, mas estes usam a língua de sinais.

Lane (1992) ressalta que a cultura surda, além da língua, é composta de literatura específica, sua própria história ao longo do tempo, história de contos de fadas, fábulas, romances, peças de teatro, anedotas, jo- 
gos de mímica. O autor ressalta ainda que algumas peças de teatro chamam a atenção para algumas atividades ridículas dos ouvintes, como conversas intermináveis pelo telefone, o pânico de serem tocados, a falta de percepção visual, a falta de expressão dos rostos, nos quais apenas os maxilares se articulam, rostos que pela sua insensibilidade negam o que as palavras mencionam. Há ainda uma grande porcentagem de casamentos endógamos. Os membros da comunidade crêem, tal como os membros de outras minorias culturais, que o casamento deve ser com outro membro pertencente à mesma minoria: o casamento com uma pessoa ouvinte é totalmente desaprovado. Ou seja, ainda permanece, implicitamente, o medo do preconceito.

Ao que parece, os surdos acabam estimulando uma postura endogâmica, característica própria às minorias. Com isso, os próprios surdos parecem estabelecer uma segregação com os ouvintes. Sentindo-se pressionados a falar, cobrados a ter de falar e escrever para conseguirem estudar e arranjar um bom emprego, acabam interpretando essas cobranças sociais como imposição e poder dos ouvintes sobre os surdos, o chamado "ouvintismo", termo que só tem sentido no interior de uma di-visão social que é também a imposição de uma forma de fazer ver e de fazer crer as divisōes do mundo social. Skliar (1998) ressalta que o problema não é a surdez, não são os surdos, não são as identidades surdas, não é a língua de sinais, mas sim as representações dominantes, hegemônicas e "ouvintistas" sobre as identidades surdas, a língua de sinais, a surdez e os surdos: "Dessa forma, a nossa produção é uma tentativa de inverter a compreensão daquilo que pode ser chamado de normal ou cotidiano" (op. cit., p. 30). Ao nomear e classificar essa desigualdade, o autor acaba por enfatizar a desigualdade, a "superioridade" que os ouvintes impõem aos surdos em poder e força, como se a referência em jogo fosse apenas a relação surdos/ ouvintes e não falante ideal/incapacidade de falar.

Vejamos, abaixo, dois depoimentos sobre a cultura surda:

José: Sabe o que é cultura surda? A cultura surda é... tipo assim, o aparelho TDD, já ouviu falar? $\mathrm{O}$ aparelho TDD é um telefone digital. $\mathrm{O}$ uso já faz parte da cultura surda. Porque, se um cara é surdo... Como surdo vai se comunicar por telefone? Não tem como. O telefone digital, o e-mail, a internet, chat, ICQ... No esporte, por exemplo, a cultura surda no esporte... O juiz, se ele for apitar, ele não ouve. Como é que faz? Tira a camisa e faz assim // balança a mão para cima //. É a cultura surda. Eu sou a favor plenamente. (...) A língua de sinais é a cultura do surdo. 
Paula: Por exemplo, um casal francês vem para o Brasil passear. Quando chega aqui vê muitos índios e muitos bebês índios. A mulher francesa não pode engravidar e gostaria de adotar um bebê índio. $O$ índio não se incomoda porque tem muitos bebês. Ela leva o bebê índio de volta à França. Lá o educa: maneiras de vestir, alimentar-se, estudar. Quando o bebê índio cresce, ele volta ao Brasil. Ao chegar aqui se identifica com os índios e sente-se mal com as roupas e o modo de agir francês. Ele, então, tira a roupa, nada, caça. Porque essa é sua raça, sua cultura. $\mathrm{O}$ surdo, quando nasce, a mãe lhe ensina a falar e a estudar. Ele não sabe sinais porque sinais é visto como preguiça para falar. O surdo cresce sem saber sinais. Aprendeu a falar desde pequeno. Um dia ele encontra surdos na rua conversando. Estranha os movimentos das mãos. Pergunta se eles são surdos e a resposta é positiva. Ele explica que também não ouve e que é igual a eles. Pergunta sobre os sinais e diz que quer aprender. Ao chegar em casa não se sente bem em falar. Não quer mais falar. Quer aprender a língua de sinais. (...) A língua de sinais no Brasil é um pouco diferente. Mas a cultura é mais ou menos igual em todo o Brasil. TDD, telefone, maneira de pensar, passear. Isso é quase tudo igual.

Para José, a cultura surda parece ser o nome dado a um conjunto de mecanismos compensatórios ou alternativos que os surdos "precisam" usar diante de sua limitação auditiva, entre eles o uso de uma língua visuo-manual, sendo esta identificada, em suas próprias palavras, como a "cultura do surdo". Já Paula concebe a cultura surda de outra forma, como se esta não fosse apreendida, como se não fosse social, mas sim natural e uniforme. A idéia aqui é de que cultura está relacionada à herança biológica, porque assim também é como a surdez é concebida. Tal idéia tem como pressuposto e base de sustentação a concepção da língua como um atributo "natural", e não socialmente constituída. Tanto num caso quanto no outro, se como mecanismo compensatório ou como atributo natural, o dado mais significativo é o de que a língua é identificada como o traço por excelência de uma suposta cultura surda. Ou seja, é fundamental para a defesa dessa cultura surda a sua legitimação por meio do uso de uma determinada língua, e não de outros traços que pudessem ser entendidos como culturais, tais como relaçoes materiais e de poder específicas, sistemas de idéias e de valores de longa duração, formas de estilização e de estetização da vida etc.

\section{Na encruzilhada}

Temos duas importantes instâncias de legitimação: um saber leigo, que reproduz uma cisão social entre a comunidade de surdos e a co- 
munidade de ouvistes, e um saber acadêmico, que oficializa essa reprodução a partir de uma chave específica, o uso da língua. Ainda que a identidade e a cultura estejam relacionadas a práticas sociais de uma complexidade muito maior, a língua, fundamentalmente ela, é tomada como o instrumento por excelência de sua constituição e definição. O significado dessa inversão, desse jogo teórico que toma a língua, num primeiro momento, como determinada pelas práticas e interações sociais e, num segundo, faz dela a definidora dessas mesmas práticas, está na legitimidade mesma desses conceitos. Está, portanto, na di-visão social que eles encerram.

As interpretações elaboradas a respeito da cultura e da identidade são, nos termos de Bourdieu (1998), disputas pelo poder de impor uma visão do mundo social, pelo monopólio de uma forma legítima de fazer ver e fazer crer as divisōes sociais. Sendo assim, tais interpretações derivam, antes de mais nada, da preocupação em submeter a essa forma legítima de fazer ver os elementos do cotidiano, de um recorte arbitrário que torne possível a visão que se pretende impor e a di-visão social empreendida por tal visão.

O fato de que essa di-visão social se faça a partir da questão lingüística demonstra que o que está por trás não é apenas a cisão entre surdos e ouvintes, mas uma outra cisão, esta interna à academia, a respeito de qual seja a forma mais verdadeira de ver - ou analisar - uma "identidade" e uma "cultura". Boa parte dessa pesquisa acadêmica negligencia a complexidade das relações entre cultura, linguagem e identidade, e isso não é casual. Essa negligência indica que tanto as informaçôes oriundas das pesquisas de campo quanto as discussóes provenientes das ciências sociais, em particular da antropologia, passam por uma recepção específica que tem interesse em matizar a questão lingüística em detrimento de outras tão importantes quanto, promovendo uma redução arbitrária da complexidade da vida social. O que está por trás é a pretensão político-científica de tornar a língua, seja qual for, o instrumento por excelência de constituição e análise de todas as formas de comportamento, de pensamento e de relaçóes sociais. Por isso os conceitos passaram a legitimar uma di-visão entre identidades lingüísticas, e não outra qualquer, embora todas as evidências apontem para o fato de que a identidade social esteja ligada a um entrelaçamento de significados e disposições sociais muito mais complexo. Por isso também a língua passa, nesse malabarismo feito pelas discussões teóricas, de elemento determinado pelas práticas e interações sociais a definidora dessas mes- 
mas práticas. Essa não é uma pretensão político-científica recente, ela remonta ao surgimento e à consolidação da lingüística perante as demais disciplinas científicas. Neste sentido, os surdos tornam-se aliados de uma luta da qual eles estão excluídos: de legitimidade entre disciplinas científicas, entre formas autorizadas de fazer crer e fazer ver as divisões do mundo social.

Nesse jogo, cabe tanto aos pesquisadores quanto aos surdos submeterem suas análises e discussões a essa forma legítima de di-visão - entre línguas - do mundo social, o que evidencia um mecanismo social de autorização e legitimação de um determinado sentido. Como se o surdo tivesse apenas uma escolha: "ou você está do nosso lado ou está contra". E, com relação ao pesquisador, é como se estivesse fadado a ser cúmplice ou crítico. ${ }^{10}$ Isso porque, na prática, afastar-se de estratégias expressivas legitimadas e de formas de pesquisa predefinidas e autorizadas pode representar o risco de uma perda de "identidade".

\section{Recebido em novembro de 2004 e aprovado em maio de 2005.}

\section{Notas}

1. Assim era também com todo aquele que, por intermédio da linguagem, não fosse considerado possuidor de atributos humanos, "(...) aquele cujo discurso não pode circular como o dos outros: pode ocorrer que sua palavra seja considerada nula e não seja acolhida, não tendo verdade nem importância (...)" (Foucault, 1970, p. 10 e 11).

2. Stokoe (1972) ressalta que isso ocorria porque os gestos eram considerados subumanos, o que aproximava o homem do animal. Gestos, sinais, ícones e ruídos vocais, nada disso era considerado linguagem, pois podia ser utilizado por animais inferiores. Ver também Thomas (1996).

3. Um exemplo disso é dado por Sacks (1998) quando comenta a história da ilha de Martha’s Vineyard, Massachusetts (EUA). Nessa ilha, em razão de uma mutação, um gene recessivo posto em ação pela endogamia, uma forma de surdez hereditária vingou por 250 anos a partir da chegada dos primeiros colonizadores, por volta de 1690. Em função dessa situação, toda a comunidade aprendeu a língua de sinais, havendo livre comunicação entre ouvintes e surdos. $\mathrm{O}$ autor ressalta que estes quase nunca eram vistos como surdos, e certamente não eram considerados de modo algum "deficientes". Mesmo depois que o último surdo morreu, em 1952, os habitantes ouvintes preservaram a língua de sinais entre si e passavam involuntariamente para essa língua no meio de uma sentença, contavam piadas, "conversavam" consigo mesmos e até sonhavam em língua de sinais.

4. Moura (2000) utiliza o termo "Surdo", com letra maiúscula, diferenciando-o dos termos "deficiente auditivo" e "surdo". Para a autora, o termo "Surdo" refere-se ao indivíduo que, tendo uma perda auditiva, não é caracterizado pela sua deficiência, mas pela sua condição

Educ. Soc., Campinas, vol. 26, n. 91, p. 565-582, Maio/Ago. 2005

Disponível em <http://www.cedes.unicamp.br> 
de pertencer a um grupo minoritário, com direito a uma cultura própria e a ser respeitado na sua diferença. A utilização de "surdo" refere-se à condição audiológica de não ouvir.

5. Bueno (1998) ressalta que o surdo nem pode ser considerado excepcional, nem patológico. Entretanto, não pode ser considerado normal, já que sofre uma restrição (sensorial). Neste sentido, assim como outros indivíduos pertencentes a diferentes minorias (negros e gays, por exemplo), o surdo deve ser considerado membro de uma comunidade que sofre restrições. Parece acertado, para o autor, procurar distinguir a surdez da doença. Mas devese considerá-la, também, uma condição intrinsecamente adversa da referente ao negro ou ao homossexual.

6. Os dados apresentados neste trabalho foram retirados da tese de doutorado de Santana (2003). Os nomes dos sujeitos foram alterados para preservar sua identidade, salvo, evidentemente, o caso de Labourit (1994), uma vez que se trata de fonte bibliográfica.

7. A tradução para a língua portuguesa escrita foi realizada por Ana Paula Santana. Entrevista realizada em língua de sinais e escrita.

8. Para Benveniste (1988), é na linguagem e pela linguagem que o homem se constitui como sujeito. É na instância do discurso, na qual o "eu" designa o locutor, que este se anuncia como sujeito. Por isso, os pronomes pessoais são o primeiro ponto de apoio para essa revolução da subjetividade na linguagem: "A subjetividade de que tratamos aqui é a capacidade do locutor para se propor como sujeito" (Benveniste, 1988, p. 196).

9. Uma boa parte dos pesquisadores da área tem aceito a denominação do termo "cultura surda” (Moura, 1993, 2000; Quadros, 1997; Goldfeld, 1997; Sá, 1999; Skliar, 2000). No entanto, há pesquisadores, como Bueno (1998), que criticam essa postura teórica na qual o mundo passa a ser dividido em cultura ouvinte (dominadora) e cultura surda (dominada). $\mathrm{Na}$ opinião do autor, a surdez não pode ser suficiente para tornar iguais dois sujeitos como uma mulher, pobre, latino-americana vivendo em uma pequena localidade rural e surda e um homem branco, rico, europeu, vivendo em metrópole e surdo. Não existiria cultura ouvinte e dominante, mas relações sociais contraditórias de dominação de classe, gênero e etnia, que se abatem sobre as camadas populares, quer seja deficiente ou não. Apesar de suas críticas à generalização do termo "multiculturalismo", o autor não aprofunda em seu texto a discussão sobre se há ou não cultura surda e em que posição ele se coloca.

10. Segundo Bourdieu, "tão logo é retomado nas lutas entre classificações que se esforça por objetivar (a não ser que se impeça a divulgação, não há jeito de coibir tal uso), o discurso científico passa a funcionar na realidade dessas mesmas lutas: ele está fadado, portanto, a aparecer como crítico ou cúmplice, conforme a relação cúmplice ou crítica que o próprio leitor mantém com a realidade descrita" (1998, p. 112-113).

\section{Referências bibliográficas}

\section{BENVENISTE, E. Problemas de lingüistica geral I. 2. ed. Campinas: Editora da UNICAMP, 1988.}

BOURDIEU, P. A economia das trocas lingüisticas. São Paulo: EDUSP, 1998.

BUENO, J.G.S. Surdez, linguagem e cultura. Cadernos Cedes, Campinas, v. 19 , n. 46 , p. 41-56, set. 1998. 
FOUCAULT, M. A ordem do discurso. 3. ed. São Paulo: Edições Loyola, 1970 .

GEERTZ, C. A interpretação das culturas. Guanabara, RJ: Koogan, 1989. GOLDFELD, M. A criança surda. São Paulo: Plexus, 1997.

KOZLOWSKI, L. A educação bilíngüe-bicultural do surdo. In: LACERDA, C.B.F.; Nakamura, H.; Lima, M.C. (Org.). Surdez e abordagem bilingüe. São Paulo: Plexus, 2000.

LABOURIT, E. O vôo da gaivota. São Paulo: Best Seller, 1994.

LANE, H. A máscara da benevolência: a comunidade surda amordaçada. Lisboa: Instituto Piaget, 1992.

LOPES, L.P.M. Discursos de identidade em sala de leitura de L1: a construção da diferença. In: Signorini, I. (Org.). Lingua(gem) e identidade. Campinas: Mercado das Letras/FAPESP/FAEP, 2001.

MAHER, T.M. Sendo índio em português.... In: SignORINI, I. (Org.). Lingua(gem) e identidade. Campinas: Mercado das Letras/FAPESP/FAEP, 2001.

MEAD, G.H. Mind, self and society from the standpoint of a social behaviorist. Chicago: University of Chicago Press, 1934.

MOURA, M.C. A língua de sinais na educação da criança surda. In: Moura, M.C.; Lodi, A.C.; PereirA, M.C.C. (Ed.). Simpósio Internacional de Lingua de Sinais e Educação do Individuo Surdo, v. 1., São Paulo: TEC Art, 1993. p. 1-4.

MOURA, M.C. O surdo: caminhos para uma nova identidade. Rio de Janeiro: Revinter, 2000.

PERLIN, G.T.T. Identidades surdas. In: Skliar, C. (Org.). A surdez: um olhar sobre as diferenças. Porto Alegre: Mediação, 1998.

POCHE, B. A construção social da língua. In: Vermes G.; Boutet, J. (Org.). Multilingüismo. Campinas: Editora da UNICAMP, 1989.

QUADROS, R.M. Educação de surdos: a aquisição de linguagem. Porto Alegre: Artes Médicas, 1997.

ROSE, A. (Org.). Human behavior and social processes: an interactionist approach. Boston: Houghton Mifflin Company, 1962. 
SÁ, N.R.L. A educação dos surdos: a caminho do bilingüismo. Niterói: EDUFF, 1999.

SACKS, O. Vendo vozes. São Paulo: Companhia das Letras, 1998.

SANTANA, A.P.O. Reflexões neurolingüísticas sobre a surdez. 2003. Tese (Doutorado) - Instituto de Estudos da Linguagem (IEL), Universidade Estadual de Campinas (UnICAmP), Campinas.

STOKOE, W.C. Semiotics and human sign language. Mouton: The Hague, 1972.

SKLIAR, C. Um olhar sobre o nosso olhar acerca da surdez e das diferenças. In: SkLIAR, C. (Org). A surdez: um olhar sobre as diferenças. Porto Alegre: Mediação, 1998.

THOMAS, K. O homem e o mundo natural. São Paulo: Companhia das Letras, 1996. 